\title{
Correspondence
}

\section{Fibreoptic bronchoscope and unexpected failed intubation}

To the Editor:

The article by Crosby et al. claims to be based on literature with original data published between 1990 to 1996, excluding review articles, editorials and comments. However, 14 letters to the editor, 6 abstracts, 5 book chapters, 3 editorials are included in the references with 30 of them published before 1989. ${ }^{1}$ The authors have failed to place in correct perspective the role of the fibreoptic bronchoscope in the management of an unanticipated difficult airway. ${ }^{2,3}$ The only thing hindering the routine use of fibrescope in failed intubation, is lack of experience, skill and confidence that is essential under given circumstance. In an accompanying editorial Finucane addresses this issue and I agree with him. ${ }^{4}$

Simultaneous use of rigid and flexible fibreoptic laryngoscopy by two persons was described in $1990 .^{5}$ The suggestion that a rigid fibreoptic laryngoscope, such as the Bullard scope, is a modification of the twoperson, two-laryngoscope technique is inaccurate. These scopes cannot play the same role as the combined uses of rigid and flexible fibreoptic laryngoscopes.

In case of failed intubation for Cesarean section and in absence of fetal distress and difficult mask ventilation, there is no reason to awaken the patient after two failed intubation attempts. In these patients the trachea can easily be intubated with a fibreoptic bronchoscope.

I agree with the authors that most training programs lack structured training for management of difficult or failed intubation. As a result, most anesthesiologists have not had the opportunity to master the art of fibreoptic bronchoscopic airway management.

Andranik Ovassapian MD

Chicago, Illinois, USA

\section{References}

1 Crosby ET, Cooper RM, Douglas MJ, et al. The unanticipated difficult airway with recommendations for management. Can J Anaesth 1998; 45: 757-76.

2 Ovassapian A. Management of the difficult airway. In: Ovassapian A (Ed.). Fiberoptic Endoscopy and the Difficult Airway, 2nd ed. New York: Lippincott-Raven, 1996: 201-30.
3 Ovassapian A, Krejcie TC, Joshi CW. Fiberoptic vs rigid laryngoscopy for rapid sequence intubation of the trachea (Abstract). Anesth Analg 1992; 74: S229.

4 Finucane $B$. The difficult airway - a Canadian perspective (Editorial). Can J Anaesth 1998; 45: 713-8.

5 Ovassapian A. The difficult intubation. In: Ovassapian A (Ed.). Fiberoptic Airway Endoscopy in Anesthesia and Critical Care. New York: Raven Press, 1990: 135-48.

\section{REPLY:}

After the literature search was conducted, the database was circulated to project participants who had the option of adding important references to the database from their own files. Some of these were literature types which would not have been included in the structured search. Dr. Ovassapian observes that most anesthesiologists have not mastered fibreoptic bronchoscopic airway management. This reinforces our observation that its application in scenarios of unanticipated airway difficulties may sometimes be problematic.

We disagree that the Bullard rigid fibreoptic laryngoscope cannot be substituted for the two laryngoscope technique. It is used in this fashion by practitioners experienced in its use and, if fitted with a camera, provides superb airway visualization from lips to larynx.

Finally, we disagree with the suggestion that, after two failed attempts at tracheal intubation for elective Cesarean section, it is prudent to continue the anesthetic. Of the 129 American parturients who died of anesthesia-attributable complications in 1979-1990, more than half died of complications of general anesthesia, most a result of airway management problems. ${ }^{1}$ Chadwick, in an analysis of the ASA closed claims project database, noted critical events leading to maternal and neonatal injuries or death most commonly involved difficult or failed intubation, inadequate ventilation and aspiration. ${ }^{2}$

The association between delayed or failed intubation and morbidity is real. Cricoid pressure cannot provide absolute protection against aspiration in this instance. ${ }^{3-5}$ If persistent difficulties are encountered, ventilate and oxygenate the mother, protect her airway as best you can and bail out - wake ber up!

Edward Crosby $\mathrm{MD}$

Roanne Preston MD

Ottawa, Ontario 